\title{
DOCTRINA \\ El panel de expertos del transporte público
}

The public transport expert panel

\author{
Pablo Muñoz Vicuña (iD y Diego Muñoz Vicuña (iD \\ Abogados, Chile
}

\begin{abstract}
RESUMEN Con el dictamen de la Ley 20.378 en 2009, se creó un panel de expertos de transporte público, encargado principalmente de la fijación de las tarifas del Transantiago. Ahora, que han transcurrido más de diez años desde su creación, y tomando en consideración el rol que tuvo este panel en el estallido social ocurrido en Chile en octubre de 2019, este trabajo revisa su origen, sus atribuciones, su funcionamiento, su institucionalidad y su naturaleza jurídica con el objetivo de discutir los fundamentos de su creación y existencia.
\end{abstract}

PALABRAS CLAVE Panel de expertos del transporte público, naturaleza jurídica, institucionalidad, Transantiago, fijación de tarifas.

ABSTRACT The enactment of the Law 20,378 in 2009 created an Expert Panel of Public Transport in charge of setting Transantiago rates. After more than ten years since its creation and considering the role that this Panel had in the origin of the social outbreak that took place in Chile in October 2019, this work reviews the origin of them, its powers, its functioning and legal nature, in order to discuss the foundations of its creation and existence.

KEYWORDS Expert Panel of Public Transport, legal nature, institutionality. Transantiago, pricing.

\section{Introducción}

El 6 de octubre de 2019 comenzó a regir la última alza de tarifas del sistema de transporte público en Santiago. Esta fue fijada por un panel de expertos y significó un aumento de $\$ 30$ en el horario punta del Metro de Santiago, equivalente al 3,5\% de variación de la última tarifa fijada solo nueve meses atrás y la segunda mayor desde la creación del Transantiago. Producto de esta alza, cientos de estudiantes salieron a las calles a protestar, evadiendo el pago del pasaje del Metro con el objetivo de que la autoridad la dejara sin efecto. 
Para el 18 de octubre de 2019, las evasiones masivas habían dado lugar a la destrucción y al incendio de torniquetes, infraestructura y estaciones. Así, este fue el hecho que gatilló el denominado «estallido social». Un día después, con 77 estaciones del Metro de Santiago afectadas ${ }^{1}$ y multitudinarias manifestaciones a lo largo del país, el presidente Sebastián Piñera anunció la suspensión del alza de tarifas del sistema de transporte público en Santiago. ${ }^{2}$ De esta manera, uno de los mayores fenómenos sociales producidos en nuestro país, en los últimos treinta años, tuvo su origen en una medida dictaminada por un panel de expertos del transporte público.

El panel es conocido principalmente como la entidad que fija la tarifa del Transantiago y del Metro (actualmente denominada Red Metropolitana de Movilidad), aunque detenta otras competencias. Hasta la fecha, no se ha efectuado ninguna investigación con respecto a este panel, creado en 2009, en un contexto de grave crisis financiera del Transantiago. Sus miembros son desconocidos para la gran mayoría de la ciudadanía y sus atribuciones son escasamente conocidas, ${ }^{3}$ por lo que ha sido cuestionado en su diseño institucional a pesar del servicio de interés general involucrado. En este sentido, el exministro Felipe Morandé, durante la tramitación de la Ley 20.504, que modifica el régimen jurídico del transporte público concesionado, señaló:

El sistema público de transporte tiene el carácter de utilidad pública, sin embargo, carece de una regulación acorde con ese concepto cuando se compara con otros sectores regulados, como el agua potable y la electricidad, en que existe una autoridad fuerte que norma, supervisa, interviene y provee al usuario de continuidad en el servicio. En el caso del transporte público licitado de la ciudad de Santiago, esta situación no ocurre (Biblioteca del Congreso Nacional de Chile, 2018: 23).

De esta manera, considerando el rol técnico que le asiste a este panel de expertos en el funcionamiento del transporte público, ${ }^{4} \mathrm{y}$ el impacto político y ciudadano que con-

1. «Balance daños 19 de octubre 2019», Metro de Santiago, 20 de octubre de 2019 disponible en https:// bit.ly/3b3DGAp.

2. «Sebastián Piñera suspende el alza de tarifas del metro de Santiago y se decreta toque de queda», CNN Español, 19 de octubre de 2019, disponible en: https://cnn.it/3ptdfNg.

3. En la discusión de la Ley 20.504, que modifica el régimen jurídico del transporte público concesionado, el senador Navarro señaló: «Por ello, cuando me dicen que el proyecto busca impedir el alza de la locomoción en la Región Metropolitana, pues el pasaje podría llegar a 800 pesos, y que con ello evitamos que los santiaguinos paguen más, debo recordar que los valores de aquel los fija un panel de expertos, a los que desconozco [...] ¿Quién nombra a los integrantes de ese panel? ¿Qué experticia tienen?» (Biblioteca del Congreso Nacional de Chile, 2018: 65).

4. Aunque presentan diferencias en cuanto a sus composición, designación y funciones, los paneles de expertos son organismos comunes en los mercados regulados de nuestro país. En materia energética, está el panel de expertos eléctrico (DFL 4 de 2006 del Ministerio de Economía, Fomento y Reconstrucción); en servicios sanitarios, la comisión de expertos (DFL 70 de 1988 del Ministerio de Obras Públicas); en concesiones, el panel técnico (D.S. 900 de 1996 del Ministerio de Obras Públicas); y en telecomunicaciones, la comisión de peritos (Ley 18.168). Al respecto, Luis Cordero ha señalado: «Lo que pasa es que Transantiago está estructurado sobre una precaria regulación legal (Ley 18.696, artículo 3), destinada a normar la con- 
lleva sus decisiones, estimamos necesario efectuar un detallado estudio de este, desde sus orígenes hasta la fecha, con el objetivo de conocer su funcionamiento y discutir su institucionalidad. En este contexto, se persigue analizar, desde una perspectiva institucional, si el panel de expertos corresponde a un caso de función política delegada del Poder Ejecutivo a agencias reguladoras con la finalidad de evitar verse afectado por los costos políticos procedente de decisiones impopulares, como sería el alza de tarifas del sistema de transporte público en Santiago.

El trabajo está organizado en seis secciones. La primera sección revisa el origen del panel de expertos. La segunda sección explica en qué consiste el panel y describe su composición, sus funciones y el procedimiento de ajuste de las tarifas. La tercera sección muestra, a partir de la revisión de las resoluciones y actas dictadas por el panel desde su origen, los principales resultados de su funcionamiento. El análisis sobre la naturaleza del panel se presenta en la cuarta sección. En la quinta sección, se discute la institucionalidad del panel. Finalmente, la última sección presenta las conclusiones del artículo.

\section{Origen}

En febrero de 2007 entró en funcionamiento el Transantiago, un nuevo sistema de transporte público en base a contratos de concesión ${ }^{5}$ que pretendía una renovación integral al sistema, acorde a los estándares de exigencia y modernidad de una ciudad en vía de desarrollo como Santiago. Solo tres meses después de su lanzamiento, la presidenta de la República Michelle Bachelet reconoció falencias en su diseño, implementación, supervisión y fiscalización (Briones, 2009: 38). El Transantiago se convertía rápidamente, de acuerdo con la opinión de expertos (Muñoz y Ortúzar, 2009:16; Briones, 2009: 39; Gómez-Lobo, 2012: 2), políticos ${ }^{6}$ y ciudadanos (CEP, 2007: 41-42), en una de las peores políticas públicas de nuestro país.

Para abril de 2007, Transantiago ya había generado un déficit de 30 millones de dólares (Mardones, 2008: 110), lo que motivó a que, el 5 de julio de 2007, se dictara

cesión de bienes nacionales de uso público (no la regulación de un servicio de interés general), y que, por lo tanto, carece de una institucionalidad adecuada a los servicios que pretende otorgar. [...] En síntesis, eso es Transantiago: un modelo de gestión administrativa de servicios de interés general, mediante el sistema de contratos públicos» (Cordero, 2015: 452-453). Con respecto a la naturaleza jurídica de los contratos de concesión, se recomienda Bermúdez (2011: 264-266), Cordero (2015: 442-455) y Valdivia (2018: 311-317). Ahora bien, no es objeto de este estudio abordar la naturaleza jurídica de estos contratos.

5. Respecto de la naturaleza jurídica de los contratos de concesión, se recomienda Bermúdez (2011: 264266), Cordero (2015: 442-455) y Valdivia (2018: 311-317).

6. El 5 de junio de 2007, se creó una Comisión Especial Investigadora en la Cámara de Diputados, encargada de analizar los errores en el proceso de diseño e implementación del Plan Transantiago, que propuso hacer efectiva la responsabilidad de los principales funcionarios que participaron en el diseño y en la implementación del Transantiago (Cámara de Diputados, 2017).

7. Según la encuesta CEP de diciembre de 2007, para el 77\% de los usuarios el Transantiago funcionaba mal y el 63\% estimó que sus tiempos de viaje aumentaron. 
la Ley 20.206, que creó un Fondo de Estabilización Financiera por un monto de US\$ 287 millones. Durante 2007 y 2008, el gobierno tuvo que pedir cuantiosos préstamos al Metro, al Banco Estado, a ENAP y al Banco Interamericano de Desarrollo por US\$ 60 , US $\$ 150$, US $\$ 20,8$ y US $\$ 400$ millones respectivamente, e invocar el mecanismo excepcional de recursos contemplado en el artículo 32, número 20, de la Constitución Política. ${ }^{8}$ Lo anterior, le permitió al gobierno de la época obtener el $2 \%$ del presupuesto anual de 2008, equivalente a US\$920 millones (De Gregorio y otros, 2017: 32). Dicho mecanismo fue reiterado al año siguiente, a través del cual se obtuvieron otros US $\$ 469$ millones.

En ese contexto, el 6 de mayo de 2008 se presentó, desde el Ejecutivo, un proyecto de Ley que creó «un subsidio nacional para el transporte público remunerado de pasajeros» (tramitado como Boletín 5.849-15). La idea era inyectar un monto de \$190.350.00o por el período 2009-2011 al Transantiago (Biblioteca del Congreso Nacional de Chile, 2008: 6). El proyecto proponía, además, que el ministro de Transportes y Telecomunicaciones convocara a los prestadores de servicios de transporte público remunerado de pasajeros, que contaban con contratos vigentes, a procesos de renegociación de estos, para efectos de incorporar los recursos resultantes de aplicar el mecanismo de subsidio y modificar las tarifas o estándares de servicio (Biblioteca del Congreso Nacional de Chile, 2008: 11-12). Asimismo, se establecía en el artículo primero transitorio, inciso final, que el Ministerio de Transportes y Telecomunicaciones contaría "con un Comité Asesor de Expertos, al que le correspondería pronunciarse sobre la metodología, las condiciones y los términos para la renegociación a la que se refiere el inciso anterior» (Biblioteca del Congreso Nacional de Chile, 2008: 12).

Inicialmente, este Comité Asesor de Expertos únicamente debía pronunciarse sobre las nuevas tarifas y las condiciones operativas de los actuales operadores, producto de los subsidios que se establecían en el proyecto, sin considerar otras normas que regulasen su funcionamiento. Fue durante la tramitación del Proyecto de Ley, producto de una indicación del Poder Ejecutivo, que se incorporó al panel de expertos, cuyo principal mandato iba a ser fijar la tarifa del Transantiago para mantener su valor real, garantizando que el déficit del sistema fuera financiable con los subsidios que la Ley otorgara. Además, se contemplaba que el panel informara sobre los procesos de licitación de vías en ciudades distintas a Santiago y, finalmente, que asesorara técnicamente al Ministerio en materias relacionadas con su competencia (Biblioteca del Congreso Nacional de Chile, 2008: 200).

8. El artículo citado dice: «El presidente de la República, con la firma de todos los ministros de Estado, podrá decretar pagos no autorizados por ley para atender necesidades impostergables derivadas de calamidades públicas, de agresión exterior, de conmoción interna, de grave daño o peligro para la seguridad nacional o del agotamiento de los recursos destinados a mantener servicios que no pueden paralizarse sin serio perjuicio para el país. El total de los giros que se hagan con estos objetos no podrá exceder anualmente del dos por ciento (2\%) del monto de los gastos que autorice la Ley de Presupuestos». 
La incorporación de este órgano tuvo amplio respaldo en el Congreso, aprobándose por unanimidad las indicaciones propuestas (Biblioteca del Congreso Nacional de Chile, 2008: 217-221, 243-245, 266 y 333). Durante su tramitación, se explicitó la necesidad de contar con un panel técnico y no político, de manera que las tarifas no dependieran de una decisión política y sus alzas no afectaran a la autoridad (Biblioteca del Congreso Nacional de Chile, 2008: 349), ${ }^{9}$ que fuera independiente y que pudiera estudiar la implantación de una tarifa razonable (Biblioteca del Congreso Nacional de Chile, 2008: 288-289)..$^{10}$ Por otro lado, el ministro de la época, René Cortázar, afirmaba que este panel, además de tener la función de ajustar las tarifas, iba a determinar el valor necesario para que, en 2015, el sistema se autofinanciara sin necesidad del subsidio transitorio. Sin embargo, a pesar de la trascendencia del panel, no existió discusión legislativa en relación con la creación, el funcionamiento, las atribuciones o la naturaleza jurídica de él. Este proyecto concluyó con la dictación de la Ley 20.378, que creó formalmente un panel de expertos del transporte público.

\section{El panel de expertos}

\section{Composición, duración y designación}

Según la Ley 20.378 de 2009, específicamente en su artículo 16, inciso primero, el panel de expertos está conformado por tres integrantes ${ }^{11}$ que duran seis años en sus cargos y son designados de la siguiente forma:

- Dos de ellos son nombrados por el Ministerio de Transportes y Telecomunicaciones, cada uno a partir de una terna propuesta por el Consejo de Alta Dirección Pública, ${ }^{12}$ con el voto favorable de cuatro quintos de sus miembros.

- Un integrante nombrado por el Ministerio de Transportes y Telecomunicaciones, a partir de una terna propuesta por los decanos de las facultades de ingeniería, y de Economía y Administración de las universidades que se encuentran

9. En este sentido, sostenía el diputado Cristián Monckeberg: «También es relevante lo que dice en relación con el panel de expertos y las tarifas. Pienso que no es bueno ni positivo que las tarifas dependan de una decisión política. Debemos reconocer que para ninguna autoridad es agradable dar a conocer alzas de tarifas. Por eso, esas alzas se deben analizar desde un punto de vista absolutamente técnico».

10. Señalaba la senadora Evelyn Matthei: «Vamos a contar con un panel independiente, el cual empezará a estudiar la implantación de una tarifa razonable, que puedan pagar los santiaguinos; vamos a empezar a ver cómo comenzar a bajar costos».

11. Para desempeñarse como miembro del panel, se requiere estar en posesión de un título profesional de una carrera de, a lo menos, diez semestres de duración, otorgado por una universidad o instituto profesional del Estado o reconocido por este, en el área de la administración, de la gestión, de la ingeniería, de la economía, de las finanzas o jurídica, o de un título de nivel equivalente en dichas áreas otorgado por una universidad extranjera, y acreditar una experiencia profesional de, a lo menos, cinco años.

12. El mecanismo de designación se encuentra regulado por el Decreto Supremo 129, de 2009, del Ministerio de Transportes y Telecomunicaciones. 
acreditadas de conformidad con lo dispuesto en la Ley 20.129, que establece un sistema nacional de aseguramiento de la calidad de la educación superior (Ley 20.378, artículo 16, inciso primero, letra b).

Además, el panel cuenta con un secretario abogado, funcionario de la Subsecretaría de Transportes, que tiene, entre sus principales funciones, llevar registro de las presentaciones que se hagan al panel y de las resoluciones que este emita; levantar acta de las sesiones y asistir al panel en su administración interna y representarlo ante la Subsecretaría de Transportes en materias administrativas (Decreto Supremo Transportes y Telecomunicaciones 40, 2010: artículos 7 y 8).

La composición original del panel estuvo conformada por los miembros titulares Patricio Rojas, economista; Juan Enrique Coeymans, ingeniero civil; y José Tomás Morel, economista, quienes fueron designados por un período de 2, 4 y 6 años respectivamente. ${ }^{13}$ Actualmente, el panel está compuesto por los economistas Juan Pablo Montero, Claudio Agostini y Jorge Hermann. La tabla 1 expone, junto a estos datos, sus períodos en el cargo, así como quienes fueron miembros titulares del panel en el tiempo intermedio y quienes ejercieron o ejercen como miembros suplentes.

\section{Funciones}

Actualmente, al panel le corresponden las siguientes funciones: ${ }^{14}$

- Determinar trimestralmente el ajuste de tarifas del sistema de transporte público de la provincia de Santiago y de las comunas de San Bernardo y Puente Alto, requerido para mantener el valor real de estas, de acuerdo con la metodología ${ }^{15}$ que se establece en un reglamento. ${ }^{16}$ Todo esto, según la Ley 20.378 en su artículo 14, letra a).

- Proponer, sobre la base de estudios técnicos, modificaciones a la metodología a la que se refiere el literal anterior. Cualquier modificación a dicha metodología,

13. A pesar de que, en virtud del artículo 16 de la Ley 20.378 duran seis años en sus cargos, según el artículo 9 transitorio de dicha ley los expertos nombrados por primera vez por el Ministerio, a partir de la terna de la alta dirección pública, duraban en su cargo uno seis años y el otro, dos años. El tercer integrante nombrado por primera vez por el Ministerio, a partir de la terna propuesta por los decanos de las Facultades de Ingeniería y de Economía y Administración de universidades acreditadas, duraba cuatro años.

14. Cuando se dictó la Ley 20.378 en 2009, el panel tenía cinco funciones específicas. En 2013, a través de la Ley 20.696, se incorporó el actual literal f) del artículo 14 y, además, se modificaron y precisaron los plazos para la determinación de las tarifas. Así, con respecto al literal a), originalmente la determinación que debía hacer el panel era mensual. Con la Ley 20.696, se modificó la frecuencia a trimestral. Asimismo, con respecto al literal c), que originalmente no establecía un período para esta función, se agregó que la determinación fuera trimestral, haciendo concordante ambos períodos de determinación.

15. Esa metodología debe dar cuenta de las variaciones de los costos del sistema de transporte público remunerado de pasajeros, de forma de no incrementar la diferencia entre costos e ingresos del sistema.

16. Reglamento dictado mediante el D.S. 140 del 14 de diciembre de 2009 del Ministerio. 
Tabla 1. Miembros del panel de expertos (2010-2021)

\begin{tabular}{|c|c|c|}
\hline & Miembros titulares & Miembros suplentes \\
\hline 1) & José Tomás Morel Lara (2010-2014) & María Eugenia Wagner Brizzi (2010-2016) \\
\hline 2) & Patricio Rojas Ramos (2010-2012/2012-2018) & Hernán de Solminihac Tampier (2010-2016) \\
\hline 3) & Juan Enrique Coeymans Avaria (2010-2014/2014-2020) & Juan de Dios Ortúzar Salas (2014-2020) \\
\hline 4) & Juan Pablo Montero Ayala (2016-2022) & Patricia Viviana Galilea Aranda (2016-2022) \\
\hline 5) & Claudio Andrés Agostini González (2018-2024) & Luis Ignacio Rizzi Campanella (2020-2026) \\
\hline 6) & Jorge Ernesto Hermann Anguita (2020-2026) & \\
\hline
\end{tabular}

debe contar con el informe favorable del Panel. Todo esto, según la Ley 20.378 en su artículo 14, letra b).

- Determinar trimestralmente, para el sistema de transporte público de la provincia de Santiago y de las comunas de San Bernardo y Puente Alto, el nivel de tarifas que permita, anualmente, financiar el sistema dado el monto del subsidio que establece la Ley. ${ }^{17}$ Todo esto, según la Ley 20.378 en su artículo 14, letra c).

- Evaluar los procesos de determinación de las tarifas en las bases de licitación de uso de vías y servicios complementarios, de haberlos, propuestos por el Ministerio de Transportes y Telecomunicaciones, e informar si ellas se ajustan a los criterios definidos en la ley. Todo esto, según la misma ley en su artículo 14, letra d).

- Pronunciarse sobre otros requerimientos de opinión o asesoría técnica solicitados por el Ministerio mencionado, los que no necesariamente deben circunscribirse a materias de transporte relacionadas con Santiago. Todo esto, según la misma ley en su artículo 14, letra e).

- Pronunciarse sobre la metodología, las condiciones y los términos de la implementación de modificaciones en las condiciones económicas y en la operación de los servicios de transporte público remunerado de pasajeros en las zonas geográficas distintas a Santiago. ${ }^{18}$ Siempre según la Ley 20.378, pero esta vez en su artículo 14, letra f).

- Convocar, cada dos años, a entidades especializadas en la realización de un estudio de evaluación externa al sistema de transporte público remunerado de pasajeros en Santiago con el objetivo de evaluar el funcionamiento del sistema, en base a lo cual podrá proponer un ajuste a los montos de subsidio, para su con-

17. Esta facultad se complementa con lo dispuesto en el artículo décimo transitorio de la Ley 20.378, que dispone que el nivel de tarifas deberá ser determinado de «forma que su evolución sea consistente con el monto del aporte especial y el subsidio permanente».

18. Facultad incorporada en 2013 en la Ley 20.696. 
sideración en la discusión del correspondiente proyecto de Ley de Presupuestos del Sector Público. También según la Ley 20.378 en su artículo 3 transitorio, inciso tercero (Biblioteca del Congreso Nacional, 2013: 45). ${ }^{19}$

\section{Ajuste y nivel de tarifas}

Con respecto a estas funciones, es importante precisar las diferencias entre los literales a) y c), ya que ambas se vinculan a la determinación de tarifas, aunque por causas distintas.

En el caso del ajuste de la tarifa, se refiere a la necesidad de adecuar esta, a partir de un cálculo de un polinomio que considera la variación ponderada de factores de los costos más relevantes del servicio prestados por los concesionarios: i) el precio del diésel; ii) el índice del costo de la mano de obra nominal; iii) el IPC; iv) el tipo de cambio del dólar; v) índice de costos de energía eléctrica; y vi) el índice de costos de potencia eléctrica. ${ }^{20}$ Para esta función, existe un reglamento que determina la metodología para determinar trimestralmente el ajuste de las tarifas, por lo tanto, el panel no cuenta con espacio de discrecionalidad (Puga, 2017: 89). ${ }^{21}$

Por otra parte, en el caso del nivel de tarifas, tiene por objeto determinar el monto de las tarifas considerando el financiamiento anual de todo el sistema y el subsidio que existe para ello, por lo que el alza de tarifas debe efectuarse, de manera anticipada, para conservar un saldo positivo en el flujo neto (Centro de Transporte Sustentable de México A.C. - World Resources Institute México, 2017: 64-65). Para efectos de esta fijación tarifaria no se establece metodología alguna, por lo que el panel debe resolver a partir de la información que le proporcione el Directorio de Transporte Público Metropolitano. De esta manera, para este segundo cálculo, el panel tiene mayores espacios de discrecionalidad. Un ejemplo de esta última función es el aumento de tarifa de $\$ 20$ para el Transantiago y el Metro del 19 de febrero de 2018. En ese caso, el panel fundó el alza en el mayor costo que para el sistema de transporte público implicaron las nuevas líneas 3 y 6 del Metro de Santiago y del Metrotrén Nos. Así, el panel estimó que los recursos presupuestarios para 2018 y la proyección de ingresos del sistema con las tarifas

19. Esta función fue incorporada en 2013 por la Ley 20.696. Según consta de la historia de dicha ley, su objetivo era que las tarifas subieran únicamente producto de la inflación y no por efecto del déficit del sistema.

20. Hasta 2019, se consideraban otros factores, como el valor de lubricantes, el valor de los neumáticos nuevos, el tipo de cambio para el euro y el índice promedio de productos importados del sector industrial, los que fueron eliminados. A su vez, se incorporaron como nuevos factores los literales v) y vi) referidos. De esta manera, la última modificación al DS 140, de 2009, redujo de 8 a 6 los factores.

21. Si bien Puga (2017) no es abogado y no profundiza en su concepto de «discrecionalidad», entendemos que el término se encuentra bien aplicado desde la perspectiva del derecho administrativo, es decir, como una potestad reconocida por el derecho a la Administración, en virtud de la cual goza de un espacio de autodeterminación, de un margen o libertad de decisión para elegir entre varias alternativas o soluciones posibles (Cordero, 2015: 83; Valdivia, 2018: 224). 
vigentes no resultaban suficientes para hacer frente a los costos del sistema durante ese período. ${ }^{22}$

\section{Procedimiento para el ajuste del nivel de tarifas}

Cada vez que el panel propone un determinado nivel de tarifas debe informarlo al Ministerio. Todo esto, con el propósito de que este último pueda formular sus observaciones dentro del plazo de los diez días hábiles siguientes. Una vez recibidas estas observaciones, el panel emite una resolución definitiva con respecto al nivel de tarifas, la cual es vinculante para el Ministerio. El nuevo nivel de tarifas se informa al Ministerio, a lo menos treinta días antes de su aplicación, para que este lo sancione ${ }^{23}$ mediante resolución. Así, debe ser implementado por el correspondiente prestador de servicios complementarios en el plazo que se le indique.

Los aumentos o disminuciones de tarifas que determine el panel, se expresan como un cambio porcentual de las tarifas y se aproximan al múltiplo de diez pesos más cercano. En todo caso, dichas variaciones de tarifas no pueden exceder el valor del $5 \%$ en cada mes. Todo esto, según la Ley 20.378 en su artículo 15.

A pesar de que la ley señale que al panel le corresponde determinar los aumentos o disminuciones en las tarifas, mientras exista el subsidio al transporte público establecido en la Ley 20.378 la tarifa no puede bajar, de conformidad a lo dispuesto en el inciso cuarto del artículo 15 de dicha ley, que establece que, «mientras esté vigente el subsidio al que se refiere el artículo tercero transitorio de la presente ley, el panel no podrá determinar una reducción en el nivel general de tarifas» (Puga, 2017: 89). De esta manera, aun cuando el resultado del indexador pueda dar un valor de ajuste negativo por la caída de los precios de cada uno de los factores, el panel no puede bajar la tarifa, ya que esta se encuentra subsidiada.

Por otra parte, este procedimiento debe complementarse con lo dispuesto en la Ley 21.184, dictada tres días después del estallido social. Conforme a dicha ley, el presidente de la República cuenta con la facultad de dejar sin efecto o limitar el aumento de tarifas dispuesto por el panel, mediante decreto expedido por el Ministerio de Transportes y Telecomunicaciones y suscrito por el Ministerio de Hacienda, el que deberá considerar, además, el incremento en los recursos que permitan mantener el equilibrio financiero del sistema de transporte público remunerado de pasajeros de la provincia de Santiago y las comunas de San Bernardo y Puente Alto, o compensar el valor real de la tarifa.

\footnotetext{
22. «Acta 136, nonagésima quinta sesión ordinaria panel de expertos Ley 20.378 », 22 de diciembre de 2017, disponible en https://bit.ly/3d7ntuJ.

23. Para efectos de este trabajo, se utiliza el vocablo «sancionar» conforme a las dos primeras definiciones otorgadas por la Real Academia Española, esto es «dicho de una autoridad competente: ratificar una ley o disposición mediante sanción», o «autorizar o aprobar cualquier acto, uso o costumbre», y no como la manifestación de la actividad de policía de la Administración Pública que la autoriza a aplicar una sanción tipificada por el ordenamiento jurídico una vez cometida una infracción administrativa (Bermúdez, 2011: 272).
} 
Esta ley, tramitada en dos días y que irrogó un mayor gasto fiscal de \$3.500 millones de pesos solo para 2019 con cargo a los recursos de la partida presupuestaria del Ministerio de Transportes y Telecomunicaciones, ${ }^{24}$ fue creada con el objeto de dejar sin efecto el alza de \$30 en horario punta en la tarifa de transporte público de Santiago decretada el 1 de octubre de 2019 y otorgarle mayores facultades al presidente para limitar las alzas que pueda determinar el panel, según consta en el mensaje presidencial del proyecto de ley:

Sin perjuicio de lo anterior, la última alza de tarifas decretada por el panel de expertos, creado por la Ley 20.378, a partir del 6 de octubre de 2019, gatillada por el alza de costo del sistema, reveló la necesidad de que el Ejecutivo cuente con herramientas legales que le permitan ponderar antecedentes de orden económico y social al momento de aplicar un alza de tarifas, $y$, de manera excepcional y fundada, poder dejar sin efecto o limitar un alza de tarifas decretada de conformidad al procedimiento y los órganos señalados en la Ley 20.378 (Biblioteca del Congreso Nacional de Chile, 2019: 3).

Además de las atribuciones del panel de expertos para determinar un nuevo nivel de tarifas y de la facultad del presidente de la República para dejarlo sin efecto o limitarlo, el Ministerio de Transportes y Telecomunicaciones también puede realizar aumentos extraordinarios de tarifas, los que no tienen un límite de monto ni de fecha para su aplicación. Todo esto, según el artículo 15, inciso quinto de la Ley 20.378. Con respecto a esta facultad extraordinaria, el Ministerio ha señalado, en fallo de recurso de protección (Sentencia de la Corte de Apelaciones de Santiago rol 15.131-2016, 2016: 7-8), que dicho ajuste debe cumplir con los siguientes requisitos:

- Solo puede consistir en aumentos de tarifa.

- No tienen un límite legal de monto ni de fecha para su aplicación.

- No se establece a su respecto una metodología para su determinación, por lo que es una facultad discrecional.

- No está limitado el ejercicio de dicha facultad a algún tipo de tarifa, por lo que procede con respecto a cualquier de ellas.

- No se requiere consulta ni aprobación del panel de expertos.

24. De acuerdo con el informe financiero del proyecto de ley (mensaje 205-367). Para los años siguientes, el presupuesto se consideró en la Ley de Presupuesto respectiva. 


\section{Ejercicio}

Según se estipula en el artículo 19 de la Ley 20.378, el panel se debe reunir periódicamente al menos una vez al mes. ${ }^{25}$ Así, es la Subsecretaría de Transportes el órgano que otorga la asistencia administrativa para su funcionamiento.

Para cumplir sus obligaciones, el panel puede encomendar estudios y contratar asesores, que son financiados por el Ministerio de Transportes y Telecomunicaciones, de acuerdo con un presupuesto aprobado anualmente para este fin. Para sesionar, el panel requiere un quórum mínimo de dos miembros. De las deliberaciones y acuerdos del panel, se deja constancia en las actas respectivas y en las resoluciones que se emitan. Las decisiones del panel se toman con la aprobación de al menos dos de sus miembros. Todo esto según el inciso final del artículo 19 de la Ley 20.378.

\section{El funcionamiento del panel de expertos desde su origen}

Para analizar el funcionamiento del panel, se analizaron todas las actas (187) y resoluciones sobre tarifas de transporte público (89) dictadas por él desde el 15 de febrero de 2010 hasta el 16 de febrero de $2021 .^{26}$

\section{Ejercicio de funciones del panel ${ }^{27}$}

En relación con estas funciones, desglosadas en la figura $1,{ }^{28}$ se efectúan algunas precisiones o aspectos a destacar:

- En estos diez años de funcionamiento, el panel únicamente no ha ejercido su función de evaluar los procesos de determinación de tarifas en bases de licitación de uso de vías del artículo 14 letra d), toda vez que no consta que haya sido requerido por el Ministerio para esa función. ${ }^{29}$

25. Los integrantes del panel reciben una dieta mensual equivalente a 30 unidades tributarias mensuales como base, más 20 unidades tributarias mensuales por cada sesión, y no pueden percibir, en total, más de 70 unidades tributarias mensuales considerando la dieta proporcional al período y el pago por asistencia a sesiones.

26. Para más información, véase «Comunicado de prensa: Panel de expertos del transporte público», Panel de expertos del transporte público, 22 de octubre de 2019, disponible en https://bit.ly/3JhjBqa.

27. Se hace presente que, en este trabajo, no se contempló la facultad otorgada al panel a través del artículo 1 transitorio de la Ley 20.504, que modifica el régimen jurídico del transporte público concesionado. En virtud de dicha facultad, en el marco de un procedimiento en que el Ministerio podía poner término anticipado a una concesión previa indemnización, el panel estaba habilitado para fijar el monto de esta en caso de desacuerdo entre las partes. Actualmente, esta facultad se encuentra extinta — podía ser utilizada después de treinta días de publicada la referida ley, esto es, desde el 19 de marzo de 2011, y hasta dentro de dos años contado desde la misma fecha- y nunca fue ejercida.

28. Para todos los efectos de los artículos 14, letra a), ajuste de tarifas, y 14, letra c), nivel de tarifas, se consideran solamente los casos en que hubo alza, no aquellos que, discutiéndose esta, se haya determinado no aplicar.

29. Lo más cercano fue la presentación, en agosto de 2017, según consta en Acta del Panel 13o, que le hizo 


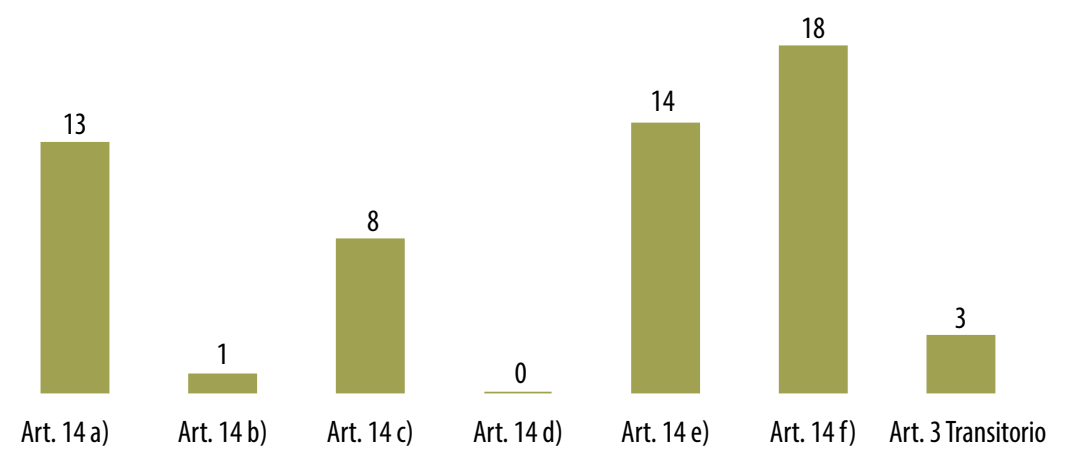

Figura 1. Número de casos que el panel ha hecho ejercicio de cada una de sus funciones

- Aunque el panel no ha propuesto cambios en la metodología para el cálculo de ajuste de tarifas del artículo 14 letra b), sí tuvo que emitir su pronunciamiento favorable con respecto a la modificación del Decreto Supremo 140 de 2009 efectuada por el Decreto Supremo 16 de 2019, ambos del Ministerio.

- El panel, con respecto a la función de asesoría técnica del artículo 14, letra e), se ha pronunciado en materias diversas, como la modificación de contratos de concesión de uso de vías para prestación de servicios de transporte público; ${ }^{30}$ diferencias en la ejecución de contratos de concesión entre el Ministerio y concesionarios $^{31}$ o perímetros de exclusión. ${ }^{32}$

- En cuanto a la función establecida en el artículo 14, letra f), el panel se ha pronunciado, por ejemplo, favorablemente con respecto a la metodología, las condi-

el Secretario Técnico del Directorio de Transporte Público Metropolitano, quien efectuó una presentación respecto de las nuevas bases de licitación del sistema de transporte público de la ciudad de Santiago. Durante la exposición, se efectuaron algunas consultas por los panelistas, en materias como el control de la evasión y las mejoras en los índices de regularidad y frecuencia. Para más información, véase «Acta 130, nonagésima primera sesión ordinaria panel de expertos Ley 20.378», 25 de agosto de 2017, disponible en https://bit.ly/3fh3TPe.

30. «Acta 74, vigésima sesión extraordinaria de panel de expertos Ley 20.378», 7 de agosto de 2014, disponible en https://bit.ly/3u7ZToF.

31. Para más información, véase «Acta 78 , vigésima primera sesión extraordinaria de panel de expertos Ley 20.378, 7 de noviembre de 2014, disponible en https://bit.ly/3swD5OX; y «Acta 81, vigésima segunda sesión extraordinaria de panel de expertos Ley 20.378», 23 de diciembre de 2014, disponible en https://bit. ly/3wiAlai.

32. Los perímetros de exclusión corresponden a una regulación mediante la cual se establecen condiciones de operación y utilización de vías cuando se requiera un ordenamiento o mejora en la calidad de los servicios, por un determinado plazo y en un área geográfica en que no se encuentre vigente una concesión de uso de vías. Se encuentra normado en el artículo 42 del Decreto Supremo 212, de 1992, del Ministerio de Transporte y Telecomunicaciones, y en el artículo 3 de la Ley 18.696. Para más información, véase «Acta 95, vigésima sexta sesión extraordinaria de panel de expertos Ley 20.378», 11 de noviembre de 2015, disponible en https://bit.ly/3ctT76ry «Acta 116, octogésima tercera sesión ordinaria panel de expertos Ley 20.378», 26 de diciembre de 2016, disponible en https://bit.ly/39mImBd. 
ciones y los términos de negociación con prestadores de servicios de transporte público en ciudades distintas de Santiago ${ }^{33}$ y a la metodología, condiciones y términos de la implementación de perímetros de exclusión. ${ }^{34}$

- Con respecto al artículo 3 transitorio, incorporado en 2013 en virtud de la Ley 20.696, se han licitados tres estudios para que evalúen, de manera externa, al sistema de transporte público remunerado de pasajeros en Santiago en 2014, 2016 y 2018.35 Se destaca que el primero sirvió de base para las modificaciones realizadas a la Ley 20.378 por la Ley $20.877^{36}$ (Biblioteca del Congreso Nacional, 2015: 4-5).

\section{Alza de tarifas del panel e inflación período}

La figura 2 muestra un alza continua de las tarifas del metro y del Transantiago, y la compara con la inflación en el mismo período. Para lo anterior, se muestra cómo hubiera evolucionado la tarifa troncal adulto, que comenzó en \$410, si es que solo se hubiera ajustado por el índice de precios al consumidor (IPC).

Se distinguen cinco períodos. El primero de marzo de 2010 a mayo de 2012, en que hubo once alzas de tarifas, aumentando la tarifa troncal de buses de $\$ 410$ a $\$ 590(43,9 \%$ nominal) y el metro en hora punta de $\$ 470$ a $\$ 670$ (42,5\% nominal). Luego, se distingue un período estable de mayo de 2012 a noviembre de 2013, sin alzas. A continuación, en el tercer período, hubo cuatro alzas, de noviembre de 2013 a diciembre de 2014, en las que la tarifa troncal de buses aumentó de $\$ 590$ a $\$ 640(8,6 \%$ nominal $)$ y el metro en hora punta de $\$ 670$ a $\$ 720$ ( $7,4 \%$ nominal). Posteriormente, le sigue un período de tres años, de diciembre de 2014 a diciembre de 2017, sin alzas (Resolución Panel 5, 2015). ${ }^{37}$ Finalmente, hubo un último período de cuatro alzas de diciembre de 2017 a octubre

33. Para más información, véase «Acta 30, décimo octava sesión ordinaria de panel de expertos Ley 20.378, 15 de julio de 2011, disponible en https://bit.ly/3u6AXov; $y$ «Acta 110, trigésima primera sesión extraordinaria panel de expertos Ley 20.378», 12 de septiembre de 2016, disponible en https://bit.ly/31tndko.

34. Para más información, véase «Acta 80 , quincuagésima novena sesión ordinaria de panel de expertos Ley 20.378», 23 de diciembre de 2014, disponible en https://bit.ly/3ctqnei; y «Acta 104, vigésima octava sesión extraordinaria del panel de expertos Ley 20.378», 30 de mayo de 2016, disponible en https://bit. ly/3rxO4Go.

35. El primero adjudicado a la consultora internacional Embarq, disponible en https://bit.ly/32vyK6T; el segundo realizado por la consultora CTS Embarq de México, disponible en https://bit.ly/3ErcRT6; el último adjudicado a la consultora brasileña «Projecto 34», disponible en https://bit.ly/32Bmdyn.

36. Que, entre otras modificaciones, aumentó el monto total del subsidio al transporte para 2015 a 2017 y estableció como una alternativa para el cálculo del límite máximo que se puede reajustar anualmente en la Ley de Presupuestos la creación de una metodología de reajuste, establecida mediante Decreto Supremo, que comprenda de manera efectiva las proyecciones de variaciones de los costos del sistema.

37. Aunque requiere un análisis mayor, llama la atención el período de tres años sin alzas, que podría explicarse por la expectativa de la promulgación de la Ley 20.877, que retrasó la implementación de un alza, así como el favorable impacto que tuvo la modificación de esta ley, que estableció un aporte adicional al subsidio para 2015, 2016 y 2017 de hasta $\$ 120.00 .000$ miles. 


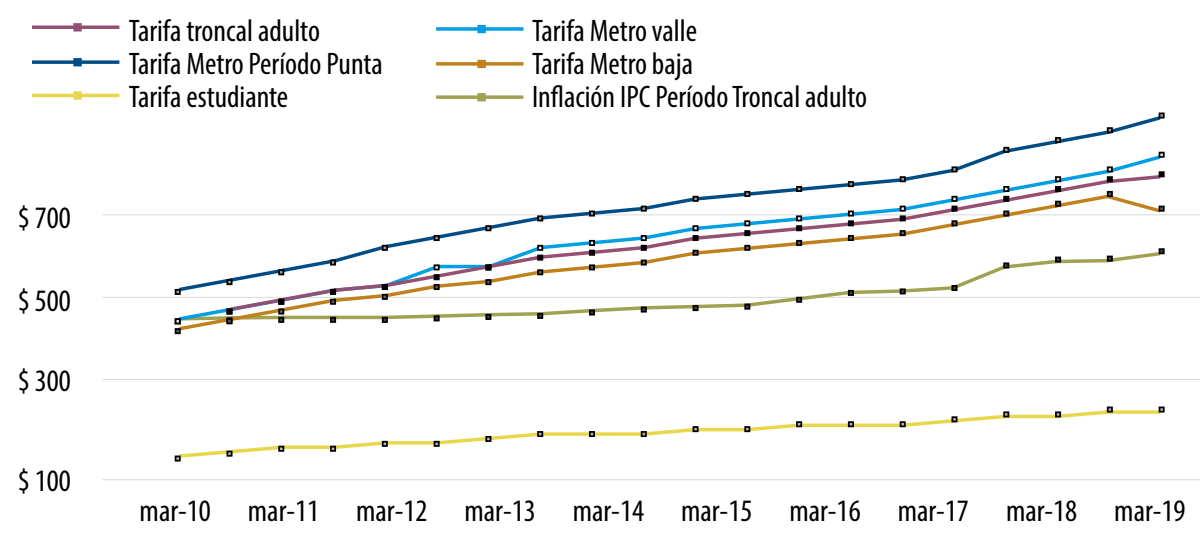

Figura 2. Evolución alza de las tarifas

de 2019, en que la tarifa troncal de buses aumentó de $\$ 640$ a $\$ 710$ (10,9\% nominal) y el metro en hora punta de $\$ 720$ a $\$ 830$ ( $15,3 \%$ nominal)..$^{38}$

De esta manera, si la tarifa de buses troncal se hubiera ajustado únicamente por la inflación (34,8\%), la tarifa, a octubre de 2019, sería de \$553 y no de \$710 (73\% inflación), como es actualmente. En otras palabras, el Transantiago ha aumentado sus tarifas aproximadamente el doble de lo que debió haber aumentado por concepto de la inflación. Lo anterior se explica por el hecho de que las tarifas no se ajustan únicamente por el alza en el nivel de costos más relevantes del concesionario, según el artículo 14, letra a), de la Ley 20.378, sino también porque las tarifas se nivelan, para el financiamiento de todo el sistema de transporte público de la provincia de Santiago, según la letra c) del mismo artículo y ley.

Por otra parte, se destaca que, aunque el artículo 15 de la Ley 20.378 establezca que, mientras esté vigente el subsidio al transporte público, el panel no podrá determinar una reducción en el nivel general de tarifas, en los diez años de funcionamiento haya habido una reducción, aunque específica, en la última alza decretada en octubre de 2019 que dio origen al estallido social. En esa oportunidad, la tarifa del metro, en el horario bajo, disminuyó de $\$ 670$ a $\$ 640$.

\section{Naturaleza jurídica del panel de expertos}

\section{No ejerce jurisdicción}

Una de las principales discusiones que se da con respecto a los paneles de expertos es si, atendida las facultades que detentan para resolver discrepancias, ejercen jurisdicción, entendida como el poder-deber de conocer y resolver, por medio del proceso

38. Cabe recordar que la última tarifa del panel fue dejada sin efecto por el presidente de la República mediante el Decreto Supremo 96, de 2019, del Ministerio de Transportes y Telecomunicaciones y del Ministerio de Hacienda, conforme a la facultad otorgada por la Ley 21.184 . 
y con efecto de cosa juzgada, los conflictos de interés de relevancia jurídica que se promueven en el orden temporal dentro del territorio de la República (Colombo, 1991: 41). A nuestro juicio, el panel de transportes no ejerce jurisdicción, pues no conoce ni resuelve contienda alguna. ${ }^{39}$ Sus facultades, como fue estudiado, se limitan a «determinar», «proponer», «evaluar», "pronunciar» o "convocar», pero bajo ningún motivo a «resolver»..$^{0}$ Las discrepancias que se han producido entre el Ministerio y los concesionarios han sido analizadas por el panel con el solo objeto de emitir una opinión técnica de conformidad a lo dispuesto en la letra e) del artículo 14 de la Ley 20.378 y no con la finalidad de resolverlas. ${ }^{41}$

39. En este aspecto, se asemeja al panel técnico de concesiones. De acuerdo con el artículo 36, inciso segundo, del Decreto Obras Públicas 900 de 1996, inserta en la denominada Ley de Concesiones: «el panel técnico, que no ejercerá jurisdicción, deberá emitir, de acuerdo con el procedimiento público establecido en el reglamento, una recomendación técnica, debidamente fundada, dentro del plazo de treinta días corridos, prorrogable por una vez, contado desde la presentación de la discrepancia. La recomendación será notificada a las partes y no tendrá carácter vinculante para ellas».

40. Como sí ocurriría, por ejemplo, en el caso del panel de expertos en materia eléctrica. Conforme al Decreto con Fuerza de Ley Economía, Fomento y Reconstrucción 4, de 2007, al dictamen del panel de expertos en materia eléctrica se someten diversas discrepancias (Decreto con Fuerza de Ley Economía, Fomento y Reconstrucción 4, 2007: artículo 208). Como se expresa en distintas disposiciones del cuerpo normativo citado, uno de los objetivos del panel es «resolver» las controversias producidas (Decreto con Fuerza de Ley Economía, Fomento y Reconstrucción 4, 2007: artículo 80, inciso séptimo; artículo 91, inciso final; artículo 104, inciso tercero artículo 112, inciso séptimo; artículo 131 ter, inciso tercero; artículo 134, inciso quinto, entre otras). Las referidas disposiciones han dado lugar a un amplio debate con respecto a la naturaleza jurídica del panel de expertos eléctrico y sus facultades jurisdiccionales (Vergara Blanco, 2014: 75; Evans Espiñeira y Yáñez Rebolledo, 2017: 447-451; Ferrada, 2014: 31; Zúñiga, 2005: 53). Para Vergara Blanco, el panel de expertos, en el sector eléctrico, es un Tribunal de Derecho que ejerce jurisdicción. En términos similares, Evans Espiñeira y Yáñez Rebolledo plantean que este panel no es un órgano de la Administración del Estado ni un órgano técnico-pericial, sino que un Tribunal especial que ejerce jurisdicción. Por otra parte, Ferrada sostiene que se trataría de un ente arbitral de naturaleza pública, con potestades regulatorias, y Zúñiga plantea que el panel no es un Tribunal, sino una instancia auxiliar de la administración del sistema eléctrico, con una función híbrida en cuanto tendría atribuciones administrativas y jurisdiccionales.

41. Por lo demás, ninguno de los integrantes del panel tiene conocimientos sustantivos de derecho al no ser abogados. En contraste, el panel de expertos en materia eléctrica, con respecto al cual se sostiene ejercería una jurisdicción arbitral en la resolución de discrepancias producidas entre empresas eléctricas (Vergara Blanco, 2005:216; Cordero, 2015: 48), cuenta con dos integrantes que deben ser abogados de amplia trayectoria profesional o académica y que acrediten, en materias técnicas, económicas o jurídicas del sector energético, dominio y experiencia laboral mínima de tres años (Decreto con Fuerza de Ley Economía, Fomento y Reconstrucción 4, 2007: artículo 209, inciso primero). La integración de estos abogados al panel eléctrico no se contempló en un primer momento, sino que se realizó durante la discusión de la ley respectiva, atendidas las complejidades procedimentales que subyacen a la decisión de la discrepancia técnica (Zúñiga, 2005: 56; Vergara, 2005: 209; Ferrada, 2014: 34). Para más información, véase «Acta 78, vigésima primera sesión extraordinaria de panel de expertos Ley 20.378, 7 de noviembre de 2014, disponible en https://bit.ly/3swD5OX. 
Tampoco es posible sostener que las resoluciones del panel de expertos son asimilables a una instancia arbitral. Lo anterior, aun cuando, en contratos del Transantiago (2011), se haya estipulado que, en caso de existir dos propuestas diferentes de ajuste de precios que no sea posible concordar, el Ministerio, de oficio o a solicitud del concesionario, requerirá al panel su opinión o asesoría técnica sobre cuál de las dos propuestas debiera acogerse y los fundamentos de dicha opinión o asesoría técnica. Ha sido el mismo panel el que ha decidido clarificar este asunto, dejando constancia de que las decisiones técnicas solicitadas en esta materia no constituyen arbitraje:

El panel se reserva el derecho de dar la opinión que le parezca más razonable, no teniendo que optar solamente entre la posición del Ministerio o la de la concesión en cuestión. Aceptar que solo puede ser la respuesta el dirimir entra una o la otra es aceptar que es un arbitraje y el panel no tiene facultades de arbitraje. ${ }^{42}$

\section{Es un órgano de la Administración del Estado}

Como se ha señalado, ni en la discusión legislativa ni en la Ley 20.378 se definió la naturaleza jurídica del panel con respecto a si sus integrantes son funcionarios públicos, si se aplica supletoriamente la Ley 19.880 o si sus actos son o no impugnables, entre otros.

De acuerdo con lo dispuesto en el artículo 1, inciso primero, de la Ley $18.575,{ }^{43}$ «el presidente de la República ejerce el gobierno y la Administración del Estado con la colaboración de los órganos que establezca la Constitución y las Leyes». Así, en el inciso segundo agrega que:

La Administración del Estado estará constituida por los ministerios, las intendencias, las gobernaciones y los órganos y servicios públicos creados para el cumplimiento de la función administrativa, incluidos la Contraloría General de la República, el Banco Central, las Fuerzas Armadas y las Fuerzas de Orden y Seguridad Pública, los gobiernos regionales, las municipalidades y las empresas públicas creadas por ley.

Conforme a esta normativa, sería posible sostener que el panel de expertos no es parte de la Administración del Estado. Sin embargo, creemos que, aun con las particularidades que presenta (sin personalidad jurídica y patrimonio propio, sin relación de jerarquía y sin cumplimiento de una función continua), sí es posible situarlo como órgano de la Administración del Estado. En primer término, porque está llamado a ejercer una función eminentemente pública, como lo es la fijación de las tarifas de transporte público. En segundo término, porque ha sido definido como un «órgano creado por ley» por el reglamento que regula su funcionamiento (Decreto Supremo Transportes y Telecomunicaciones 40, 2010: artículo 1). En tercer término, porque sus

42. Para más información, véase «Acta 71, quincuagésima segunda sesión ordinaria de panel de expertos Ley 20.378, 23 de mayo de 2014, disponible en https://bit.ly/39nRRAo.

43. «Ley Orgánica Constitucional de Bases Generales de la Administración del Estado». 
integrantes son íntegramente financiados por el Estado. En cuarto término, porque cuentan con competencias y un procedimiento reglado para su actuar expresamente establecido en la Ley 20.378 y en el D.S. 40 de 2010 , por lo que, a su respecto, rigen los principios de legalidad y juridicidad (Constitución Política de la República de Chile, 1980: artículos 6 y 7). Finalmente, porque dictan actos administrativos. En este sentido, a nuestro juicio, las resoluciones que dictan constituyen un acto administrativo en cuanto contienen una decisión formal -acuerdo contenido en una resolución-, el cual se lleva a efecto por medio de una resolución del Ministerio. Conforme a lo anterior, les rige, además, de manera supletoria la Ley 19.880.44

\section{Sus integrantes no son funcionarios públicos, pero sí cumplen funciones públicas}

Tal como ocurre con los integrantes del panel de expertos eléctrico (artículo 134 de la Ley 19.940), ${ }^{45}$ y como ha dictaminado la Contraloría General de la República con respecto del panel técnico de concesiones, los integrantes del Panel de Transportes no son funcionarios públicos (Resolución Exenta Transportes y Telecomunicaciones 742 del 27 de febrero de 2018, considerando séptimo), ${ }^{46}$ pero sí ejercen funciones públicas (Dictamen 51.509 de la Contraloría General de la República de 2014) ${ }^{47}$ y, por lo tanto, deben dar estricto cumplimiento al principio de probidad en todas sus actuaciones, de conformidad a lo exigido en el artículo 8 de la Constitución Política ${ }^{48}$ en relación con el artículo 52 de la Ley $18.575^{49}$ (Dictamen 25.839 de la Contraloría General de la República de 2019).

Esta función pública se manifiesta en las siguientes exigencias legales establecidas también para el panel eléctrico y de concesiones:

44. «Establece Bases de los Procedimientos Administrativos que Rigen los Actos de los Órganos de la Administración del Estado».

45. El artículo citado establece expresamente que sus miembros «no tendrán el carácter de personal de la administración del Estado».

46. En este sentido, consta de la resolución que designó, como integrante del panel de transportes, a Claudio Agostini, que la Contraloría General de la República informó que esa designación no estaba afecta al trámite de toma de razón, de conformidad a lo dispuesto en la Resolución 10, de 2017, ya que las resoluciones que designan a miembros de consejos o juntas directivas de organismos estatales, que no sean funcionarios públicos, quedan exentas de dicho trámite, pero deben enviarse a Contraloría General de la República para su registro.

47. En este sentido, este Dictamen expresa: «En este contexto, si bien las personas que componen el órgano en estudio sirven un cargo público en los términos del Estatuto Administrativo, como es posible apreciar, el desempeño de las labores mencionadas en el artículo 36 de la Ley de concesiones constituye el ejercicio de funciones públicas encomendadas por el legislador».

48. Su contenido es el siguiente: «El ejercicio de las funciones públicas obliga a sus titulares a dar estricto cumplimiento al principio de probidad en todas sus actuaciones».

49. Expresa: «Las autoridades de la Administración del Estado, cualquiera que sea la denominación con que las designen la Constitución y las Leyes, y los funcionarios de la Administración Pública, sean de planta o a contrata, deberán dar estricto cumplimiento al principio de la probidad administrativa». 
- Ley 20.880: De acuerdo con lo dispuesto en el artículo 4, número 3, de la Ley 20.880 sobre probidad en la función pública y prevención de los conflictos de intereses, los integrantes del panel se encuentran obligados a realizar una declaración de intereses y patrimonio.

- Ley 20.730, que regula el lobby y las gestiones que representen intereses particulares ante las autoridades y funcionarios: Conforme al numeral 7 del artículo 4 de dicha ley: «Son también sujetos pasivos de esta ley aquellas autoridades y funcionarios que se indican a continuación: 7) Los consejeros del Consejo de Defensa del Estado, del Consejo Directivo del Servicio Electoral, del Consejo para la Transparencia, del Consejo de Alta Dirección Pública, del Consejo Nacional de Televisión, del Instituto Nacional de Derechos Humanos, los integrantes de los Paneles de Expertos creados en la Ley 19.940 y en la Ley 20.378, y del Panel Técnico creado por la Ley 20.410, solo en lo que respecta al ejercicio de sus funciones».

- Aunque no se encuentra expresamente consagrado en la Ley 20.285 sobre acceso a la información pública el deber de transparencia activa y pasiva del panel, como sí lo está en el caso del panel de expertos eléctrico, ${ }^{50}$ según el artículo 8 transitorio de la Ley 20.285, de todas formas el panel cumpliría con algunos de los estándares allí estipulados. Así, todas las actas de las sesiones que se han llevado a cabo, la asistencia de sus integrantes a ellas y sus correspondientes remuneraciones, pueden encontrarse en el ítem «Transparencia» en el sitio web oficial del panel de experto. Asimismo, el panel ha dado respuesta a solicitudes de acceso de información pública que le han sido requeridas..$^{51}$

\section{Sus decisiones son impugnables administrativa y judicialmente}

A diferencia del panel técnico de concesiones, en que expresamente establece su impugnabilidad (Decreto Obras Públicas 900, 1996: artículo 36, inciso tercero), ${ }^{52}$ o el panel expertos de electricidad, en que se declara su carácter inimpugnable (Decreto con Fuerza de Ley Economía, Fomento y Reconstrucción 4, 2007: artículo 133; Vergara

50. Con la particularidad de que esta ley, al referirse al panel de expertos eléctrico, expresamente la asigna el carácter de órgano jurisdiccional, en su artículo 8: «y los órganos que ejercen jurisdicción, como la Dirección General de Aeronáutica Civil o el Panel de Expertos a que se refiere la Ley 19.940».

51. Para más información, véase "Acta 17, décima sesión extraordinaria de panel de expertos Ley 20.378», 24 de agosto de 2010, disponible en https://bit.ly/3dj3R6O; «Acta 18, octava sesión ordinaria de panel de expertos Ley 20.378, 10 de septiembre de 2010, disponible en https://bit.ly/3cvZbvx.

52. Este artículo de la Ley de Concesiones dispone que: «La recomendación del panel no obstará a la facultad del concesionario para accionar posteriormente ante la Comisión Arbitral o la Corte de Apelaciones de Santiago, aunque la controversia recaiga sobre los mismos hechos. En tal caso, la recomendación podrá ser considerada por la Comisión Arbitral o la Corte de Apelaciones como un antecedente para la dictación de su sentencia». 
Blanco, 2014: 78), 53 la Ley 20.378 nada señala con respecto a la impugnabilidad de las decisiones del panel de transportes, así como de aquellas dictadas por el Ministerio, que sancionan la decisión del panel e instruyen a los concesionarios implementar el alza.

En sede administrativa, ya que el panel formaría parte de la Administración Pública y sus decisiones constituirían un acto administrativo, podría quedar sujeta a alguno de los recursos contemplados en la Ley 19.880, al menos a la aclaración o rectificación contemplada en el artículo 62, considerando eventuales errores de copia, referencia o cálculos que pueda haber en las actas..$^{54}$ Luego, dependiendo de la naturaleza que se le confiera al acto, en cuanto acto trámite o final y su capacidad de dar continuidad o no al procedimiento, las actas podrían ser impugnables mediante recursos de reposición, jerárquico y el extraordinario de revisión. En nuestra opinión, aun cuando el acta no sea el acto terminal del procedimiento, sí es el que contiene la decisión.

Con respecto a las resoluciones que dicta el Ministerio, creemos que podrían ser impugnables en sede administrativa. Con todo, como se indicó, hay que tener presente que el Ministerio solo sanciona una decisión adoptada por el panel que le resulta vinculante, por lo tanto, no resulta posible para el Ministerio reconsiderar la determinación del órgano técnico (Autos en Corte de Apelaciones de Santiago rol 170- 2015: 10).55 Además, desde la perspectiva de los concesionarios, la resolución del Ministerio se trataría de un acto favorable para ellos, que le asegura los ingresos comprometidos en los contratos, los que se financian principalmente con el pago de las tarifas de los usuarios.

En sede judicial, estimamos que ambas resoluciones podrían ser objeto de impugnación por cualquier persona que se vea afectada por la decisión. En este sentido, con respecto a las alzas de las tarifas, se han interpuesto recursos de protección en contra del alza decretada por el panel y sancionada por el Ministerio, ${ }^{56}$ así como con respecto

53. Este artículo de la Ley General de Servicios Eléctricos dispone que: «El dictamen del panel de expertos se pronunciará exclusivamente sobre los aspectos en que exista discrepancia, debiendo optar por una u otra alternativa en discusión, sin que pueda adoptar valores intermedios. Será vinculante para todos los que participen en el procedimiento respectivo y no procederá ninguna clase de recursos, jurisdiccionales o administrativos, de naturaleza ordinaria o extraordinaria». Con todo, Vergara Blanco plantea que esta irrecurribilidad tiene como única excepción el recurso de protección, en la medida en que se revise únicamente el debido proceso (Constitución Política de la República de Chile, 1980: artículo 20, en relación con el artículo 19, número 3), sin que pueda analizarse el fondo de la decisión adoptada por el panel de expertos.

54. Bajo esta interpretación, las resoluciones del panel corresponderían a un «acuerdo», en los términos del artículo 3, inciso séptimo, de la Ley 19.88o. Así, el acuerdo del panel se formaliza por el acto administrativo que dicta el Ministerio: «Las decisiones de los órganos administrativos pluripersonales se denominan acuerdos y se llevan a efecto por medio de resoluciones de la autoridad ejecutiva de la entidad correspondiente».

55. En este sentido, el Ministerio ha señalado, en un Informe de un Recurso de Protección, que «existiendo una determinación del panel de expertos en esta materia, realizada de conformidad con la metodología establecida en ya citado Decreto Supremo 140, 2009, no podría el Ministerio desatender el resultado de la medición realizada por el órgano técnico encargado de evaluar el equilibrio financiero del sistema con respecto a sus costos de financiamiento y relación con las tarifas, subsidios y aportes que recibe».

56. Causa tramitada ante la Corte de Apelaciones de Santiago bajo el rol 170-2015. 
al alza extraordinaria decretada por el Ministerio, de conformidad a lo dispuesto en el artículo 15 de la Ley 20.378.57 Ambos recursos, declarados admisibles por la Corte de Apelaciones de Santiago, fueron rechazados.

\section{Discusión}

\section{Independencia del panel de transportes}

En Chile, desde la perspectiva de la regulación económica, se ha venido discutiendo la independencia y la calidad técnica de las agencias reguladoras (Pardow, 2018a: 194). En general, el debate se ha centrado en el diseño institucional de las Superintendencias (Cordero y García, 2012: 415), las que habrían sido creadas para ocupar ese rol (García y Verdugo, 2010: 266); sin embargo, se sostiene que agencias reguladoras serían también otros órganos legalmente descentralizados, como la Fiscalía Nacional Económica, el Servicio Nacional del Consumidor y la Comisión Nacional de Energía, así como órganos de naturaleza particular que intervienen en la regulación económica, como el Tribunal de Defensa de la Libre Competencia y el Panel de Expertos en Materia Eléctrica (Pardow, 2018b: 751).

Por lo anterior, resulta razonable incluir, como agencia reguladora, al panel de expertos de transportes, en cuanto se trata de un órgano colegiado, que interviene en un ámbito importante de la regulación económica, se compone por profesionales técnicos y consta de un diseño institucional que tiene por objeto asegurar independencia con respecto al Poder Ejecutivo, como se planteó en la discusión legislativa que lo creó..$^{8}$ Desde esta perspectiva, es recomendable que el panel sea un organismo técnico y principalmente autónomo del Ministerio, de manera que se garantice que sus determinaciones no se encuentran influenciadas políticamente.

Los estudios sobre agencias reguladoras distinguen entre independencia formal y de facto de estas. La primera, se manifiesta principalmente en los mecanismos de nombramiento, la independencia presupuestaria y en las competencias regulatorias (Gilardi, 2005: 140; Pardow, 2018b: 746). La segunda, se caracteriza por la autonomía, en el día a día, en las acciones adoptadas (Maggeti, 2007: 272).

Con respecto a la independencia formal, el sistema de nombramiento del panel, precedido de una terna propuesta por el Consejo de Alta Dirección Pública y por los decanos de las Facultades de Ingeniería y de las Facultades de Economía y Administra-

57. Causa tramitada ante la Corte de Apelaciones de Santiago bajo el rol 15131-2016.

58. En este sentido, sostenía el diputado Cristián Monckeberg: «También es relevante lo que dice en relación con el panel de expertos y las tarifas. Pienso que no es bueno ni positivo que las tarifas dependan de una decisión política. Debemos reconocer que para ninguna autoridad es agradable dar a conocer alzas de tarifas. Por eso, esas alzas se deben analizar desde un punto de vista absolutamente técnico». Además, señalaba la senadora Evelyn Matthei: «Vamos a contar con un panel independiente, el cual empezará a estudiar la implantación de una tarifa razonable, que puedan pagar los santiaguinos; vamos a empezar a ver cómo comenzar a bajar costos». 
ción de universidades acreditadas, constituye un contrapeso al Ministerio, que permite que el nombramiento sea técnico y no discrecional y político (primer requisito independencia formal). Sin embargo, salvo la facultad de proponer ajustes a los montos de subsidio para consideración en la discusión del correspondiente proyecto de Ley de Presupuestos, no tiene facultades normativas vinculadas a las mejoras del sistema de transporte, que siguen radicadas en el Ministerio (segundo requisito independencia formal). Asimismo, presupuestariamente depende del Ministerio y requiere de su asistencia para el funcionamiento (artículo 19 de la Ley 20.378). Lo que implica que la remuneración de sus miembros es realizada por el Ministerio, que el panel sesione en las dependencias de la Subsecretaría de Transportes y en la Dirección de Transporte Público Metropolitano, que los secretarios sean funcionarios del Ministerio y que, por ejemplo, hayan requerido asistencia del Ministerio para preparar los comunicados de prensa o ayudar en la implementación de la página web del panel. ${ }^{59}$ Todo lo anterior, limita de manera sustantiva la independencia formal que requiere este panel.

En cuanto a la independencia de facto, creemos que no ha existido la autonomía deseada en las decisiones adoptadas por el panel. Por ejemplo, la Resolución 3, de 21 de enero de 2011, fue dejada sin efecto porque:

Los asesores del Ministerio de Transportes y Telecomunicaciones dieron a conocer los objetivos de disminución de los costos del Sistema de Transporte Público, para 2011, lo cual constituye nuevos antecedentes que permiten prever una mayor holgura financiera (Resolución Panel 4, 2011).

En términos similares, en la Resolución 5 de 2015, se decidió dejar sin efectos alzas tarifarias determinadas conforme al artículo 14, letra c), por encontrarse en la fase final de su tramitación ${ }^{60}$ un proyecto de ley que introduce mejoras al sistema de transporte público incrementando el subsidio y la dictación de un decreto por parte del Ministerio de Hacienda que modifica los montos al subsidio (Puga, 2017: 90). Es decir, en ambas ocasiones, la decisión del panel de expertos fue tomada a partir de solicitudes de reconsideración del Ministerio sobre posibilidades de cambio en el marco regulatorio y económico.

59. Para más información, véase «Acta 6, cuarta sesión extraordinaria de panel de expertos Ley 20.378, 17 de marzo de 2010, disponible en https://bit.ly/2OoLnPZ.

6o. A esa fecha, 28 de octubre de 2015, según consta en la misma Resolución 5 referida, el proyecto había sido votado en particular en las Comisiones de Transportes y Telecomunicaciones y Hacienda del Senado. Asimismo, el presidente de la República, el 13 de octubre de 2015, había solicitado discusión inmediata, siendo aprobado por la sala del Senado, quedando pendiente el tercer trámite en la Cámara de Diputados. El proyecto fue promulgado recién el 25 de noviembre de 2015 a través de la Ley 20.877 , que «Introduce Mejoras al Transporte Público Remunerado de Pasajeros». 


\section{Es un órgano de composición técnica creado para cumplir una función política delegada}

Los miembros del panel son reconocidos académicos, ${ }^{61}$ todos sin afiliación política. Están mandatados principalmente para definir la tarifa del sistema con independencia del Ministerio y de los concesionarios, conforme a la situación financiera del sistema que les informa el Directorio de Transporte Público Metropolitano. Así, su objeto es evitar que la tarifa sea influenciada por intereses políticos o privados.

Sin embargo, la determinación de la tarifa no es solo una determinación técnica. Por una parte, en su fijación hay componentes políticos importantes, como la calidad del servicio, ejecución de las propuestas o decisiones de financiamiento (Puga, 2017: 90), todas materias en las cuales el panel no tiene atribuciones, ya que no es el organismo rector en materia de transporte público. Y, por otra parte, existe un costo político significativo en la determinación del alza de las tarifas. Desde esta perspectiva, la creación del panel responde a una de las explicaciones que se han dado en la literatura sobre delegación de poder por parte de políticos a agencias reguladoras, con el objeto de evitar asumir decisiones impopulares que tienen altos costos políticos (Fiorina, 1982: 48; Thatcher, 2002: 5; Gilardi, 2002: 2; Rivas, 2018: 98). ${ }^{62}$

Esta delegación ha permitido, por ejemplo, que el exministro Felipe Morandé, con respecto a un alza de las tarifas, haya señalado que no era resorte del gobierno, sino de «un panel de expertos que la ley ha dispuesto para que se cumpla el financiamiento»; ${ }^{63}$ que el exministro Pedro Pablo Errázuriz haya sostenido que "aumentos por déficit son inaceptables»; ${ }^{64}$ que el exministro Andrés Gómez-Lobo haya sostenido que «el panel de expertos le ofició al Ministerio un alza de 30 pesos hace un par de semanas atrás y en este gobierno no vamos a permitir que suba la tarifa en esos 30 pesos»; ${ }^{65}$ o que la actual ministra Gloria Hutt haya aseverado que «el panel de expertos determina el precio, no el Ministerio» y que «todo esto está fuera de lo que nosotros podemos controlar». ${ }^{66}$

61. Jorge Hermann Anguita es ingeniero comercial con mención en Economía de la Universidad de Chile y magíster en Economía de esa misma Universidad. Juan Pablo Montero es ingeniero civil y magíster en Ingeniería Hidráulica de la Pontificia Universidad Católica de Chile; master of science y doctor en Economía Industrial del Massachusetts Institute of Technology. Finalmente, Claudio Agostini es ingeniero comercial con mención en Economía de la Pontificia Universidad Católica de Chile y doctor en Economía de la Universidad de Míchigan.

62. Existen otras dos interpretaciones por las que los políticos delegan atribuciones en las agencias reguladoras. La primera, es para lograr un compromiso creíble (credible commitment) con los inversionistas privados, y la segunda, por la necesidad de resolver problemas cada vez más complejos y técnicos.

63. «Felipe Morandé: Lamento que las tarifas estén subiendo», El Mostrador, 17 de mayo de 2010, disponible en https://bit.ly/39nVbeE.

64. «Ministro Errázuriz y tarifas del Transantiago: Aumentos por déficit son inaceptables», El Dínamo, 1 de febrero de 2012, disponible en https://bit.ly/3prKXQc.

65. «Gobierno no permitirá alza de 30 pesos en el Transantiago», Radio Cooperativa, 16 de abril de 2015, disponible en https://bit.ly/2Mu6TeM.

66. «Ministra Hutt y alza de pasajes: "El panel de expertos determina el precio, no el ministerio"», 24 


\section{¿Debe existir el panel de expertos de transporte público?}

Cuando se discutió en torno a la creación del panel en 2008, el objetivo era contar con un ente técnico que determinara las alzas de las tarifas con prescindencia de cualquier decisión política en un contexto de negociación entre el Poder Ejecutivo y el Poder Legislativo con respecto al subsidio para el Transantiago. A partir de esto, resulta necesario cuestionarse el rol actual del panel.

En primer término, porque el panel no controla la operación del transporte público, la que es llevada a cabo íntegramente por el Directorio de Transporte Público Metropolitano, ${ }^{67}$ entidad a la que le corresponde la articulación, la coordinación y el seguimiento de las acciones y de los programas tendientes a gestionar el transporte público en la ciudad de Santiago. En este sentido, el panel funciona como una especie de contraparte técnica de la gestión del Directorio. En segundo término, porque, a partir de la dictación de la Ley 21.184, que permite al presidente de la República, mediante Decreto Supremo, dejar sin efecto o limitar el aumento de tarifas dispuesto por el panel, el carácter vinculante y la autonomía en las decisiones de él se reducen y la determinación de la tarifa se transforma en una discusión presupuestaria en el Congreso, especialmente si esa alza conlleva un costo político muy alto. Finalmente, porque al no resolver discrepancias, sus funciones y su nivel de discrecionalidad terminan siendo acotados, no contando con facultades más amplias, por ejemplo, de proponer recomendaciones normativas al presidente de la República, como tienen actualmente la Fiscalía Nacional Económica (Decreto con Fuerza de Ley Economía, Fomento y Reconstrucción 1, 2005, artículo 39, letra q) ${ }^{68}$ o la Comisión para el Mercado Financiero, según el artículo 5, número 24, de la Ley 21.000 de $2017 .^{69}$

De esta manera, si el objetivo del panel es principalmente asumir la responsabilidad política que conlleva un alza de tarifas el transporte público - habiendo visto que las demás funciones son consultivas-, como sostiene Puga (2017: 90), debiera removerse del panel la fijación tarifaria y radicar esta función en el Ministerio, ya que controla la operación. En consecuencia, debiera ser el Ministerio el organismo llamado a asumir los costos políticos que conlleva un alza en las tarifas. Ahora, si el objetivo es contar

horas, 16 de octubre de 2019, disponible en https://bit.ly/2YlNX4N.

67. «¿Quiénes somos?», Directorio de Transporte Público Metropolitano, disponible en https://bit. ly/3FurQwY.

68. De acuerdo con lo dispuesto en el artículo citado, el fiscal nacional económico tiene la atribución de «q) proponer fundadamente, al presidente de la República, a través del ministro de Estado que corresponda, la modificación o derogación de los preceptos legales o reglamentarios que estime contrarios a la libre competencia, como también la dictación de preceptos legales o reglamentarios cuando sean necesarios para fomentar la competencia o regular el ejercicio de determinadas actividades económicas que se presten en condiciones no competitivas».

69. De acuerdo a lo dispuesto en la norma referida, la Comisión tendrá la atribución de «proponer al Presidente de la República, a través del Ministerio de Hacienda, las normas legales y reglamentarias necesarias para asegurar el adecuado funcionamiento del mercado financiero y el cumplimiento por parte de las personas o entidades fiscalizadas de la normativa que las rige». 
con un organismo técnico que permita proponer mejoras al transporte público mediante dictación de normas técnicas, elaboración de estudios, propuestas de mejoras normativas y fijación tarifaria a partir de levantamiento de costos propia, entre otras funciones, se requeriría una institución distinta, más autónoma que el Ministerio, con más recursos y personal, y con mayor incidencia en la gestión, que actualmente radica en el Directorio.

\section{Conclusiones}

En este trabajo se ha dado a conocer y se ha analizado el panel de expertos del transporte público, el cual tuvo un rol clave en el origen del estallido social del 18 de octubre de 2019 en Chile. Para finalizar, podemos enumerar las siguientes conclusiones.

1. Hubo escasa discusión legislativa con respecto al sentido y el alcance del panel. En este sentido, no existió discusión en relación con su pertinencia, sus atribuciones, la naturaleza jurídica o institucionalidad. Únicamente, se destacó la necesidad de contar con un panel técnico y no político a cargo de las alzas de las tarifas.

2. El panel de expertos no está a cargo solamente de la fijación tarifaria del transporte público. Así, en sus diez años de funcionamiento, ha asesorado en múltiples oportunidades al Ministerio en materias vinculadas a contratos de concesión, perímetros de exclusión, evaluación de metodología de cálculos de subsidios y opiniones técnicas sobre discrepancias entre concesionarios y el Ministerio.

3. Desde marzo de 2010 a octubre de 2019, fecha de la última alza decretada, la tarifa troncal adulto ha aumentado de $\$ 410$ a $\$ 710$, y la tarifa metro período punta ha aumentado de $\$ 470$ a $\$ 830$. La tarifa escolar, por su parte, ha aumentado de \$130 a \$230. Se destaca que ha habido períodos de hasta tres años sin alzas.

4. En este mismo período, las tarifas han aumentado el doble de lo que debieron haber aumentado producto de la inflación, ya que las tarifas no se ajustan únicamente por el alza en el nivel de costos más relevantes del concesionario, según estipula el artículo 14, letra a), de la Ley 20.378, sino que también porque las tarifas se nivelan para el financiamiento de todo el sistema de transporte público de la provincia de Santiago, según estipula el artículo 14, letra c), de la Ley 20.378 de 2009.

5. El panel no resuelve discrepancias, por lo tanto, no ejerce jurisdicción ni cumple funciones arbitrales.

6. El panel es un órgano de la Administración del Estado y sus miembros, pese a no ser funcionarios públicos, sí ejercen una función pública. Por lo anterior, están sujetos al principio de probidad en sus actuaciones.

7. El panel es un órgano compuesto por profesionales técnicos llamados a cumplir una función política. Desde este prisma, la creación del panel corresponde a uno de los clásicos ejemplos en la literatura de delegación de poder del Poder Ejecutivo a agencias reguladoras, con el objeto de evitar asumir los costos políticos de decisiones impopulares, como es en este caso, el alza de transporte. 
8. Aunque el sistema de nombramiento del panel ha ayudado a su autonomía, el hecho de que presupuestariamente y para el ejercicio de sus funciones dependa del Ministerio, y que no cuente con mayores facultades, por ejemplo, de proponer normativas, reducen la independencia formal óptima que se espera de las agencias reguladoras.

9. Se ha demostrado que el panel ha decidido no aumentar las tarifas en base a solicitudes de reconsideración efectuadas por el Ministerio, justificadas en hechos futuros, como sería la probable aprobación de una ley y de dictación de un decreto. Ello, afecta su independencia de facto.

10. Estimamos que no se justifica contar con un panel de expertos, con las competencias acotadas que detenta - a cargo principalmente de la fijación tarifaria-, pero sin incidencia en la gestión del sistema. Lo anterior, ya que esa función podría ser cumplida por el Directorio en la medida en que sus metodologías de proyecciones de financiamiento del sistema estén regladas y sus decisiones sean motivadas y transparentadas a la ciudadanía. En ese caso, las tarifas corresponderían siempre al resultado de una ecuación (como ocurre ahora con el ajuste de tarifas).

11. Lo anterior no obsta, atendido los cuantiosos recursos involucrados y la necesidad de mejoras continuas en el funcionamiento del sistema, que pueda discutirse la existencia de un panel de expertos como organismo técnico asesor, con más recursos y personal, encargado de evaluar el sistema, elaborar estudios y con facultades de proponer mejoras normativas.

\section{Referencias}

BERmúdez, Jorge (2011). Derecho administrativo general. Santiago: Thomson Reuters.

Biblioteca del Congreso Nacional de Chile (2008). Historia fidedigna del establecimiento de la Ley 20.378: Crea un subsidio nacional para el transporte público remunerado de pasajeros. Santiago: Biblioteca del Congreso Nacional de Chile. Disponible en https://bit.ly/3iUsMjB.

-. (2013). Historia fidedigna de la Ley 20.696: Modifica la Ley 20.378 que crea un subsidio nacional al transporte público remunerado de pasajeros, incrementando los recursos del subsidio y creando el Fondo de Apoyo Regional (FAR). Santiago: Biblioteca del Congreso Nacional de Chile. Disponible en https://bit.ly/2M7qWA1.

-. (2015). Historia fidedigna de la Ley 20.877: Introduce mejoras al transporte público remunerado de pasajeros. Santiago: Biblioteca del Congreso Nacional de Chile. Disponible en https://bit.ly/39nLFrz.

-. (2018). Historia fidedigna de la Ley 20.504: Modifica el régimen jurídico del transporte público concesionado. Santiago: Biblioteca del Congreso Nacional de Chile. Disponible en https://bit.ly/2Zq1Ous.

-. (2019). Historia fidedigna de la Ley 21.184: Faculta al presidente de la República para dejar sin efecto o limitar un alza de tarifas en el transporte público de pasajeros, en las condiciones que indica. Santiago: Biblioteca del Congreso Nacional de Chile. Disponible en https://bit.ly/39m9Nve. 
Briones, Ignacio (2009). «Transantiago: Un problema de información». Estudios Públicos, 116: 37-91. Disponible en https://bit.ly/3ok9u8j.

CÁmARA DE Diputados (2007). Informe de la Comisión Especial Investigadora encargada de analizar los errores en el proceso de diseño e implementación del Plan Transantiago. Valparaíso: Cámara de Diputados, Congreso de la República de Chile. Disponible en https://bit.ly/2N2kGu1.

Centro de Transporte Sustentable de México A.C.-World Resources InstiTUTE MÉxico (2017). Informe de la evaluación externa al sistema de transporte público remunerado de pasajeros de la provincia de Santiago y de las comunas de San Bernardo y Puente Alto. Disponible en https://bit.ly/3cgFQia.

Cordero, Luis (2015). Lecciones de derecho administrativo. Santiago: Thomson Reuters. Cordero, Luis y José Francisco García (2012): «Elementos para la discusión de Agencias Independientes en Chile. El caso de las Superintendencias». Anuario de Derecho Público Universidad Diego Portales, 1: 415-435. Disponible en https://bit.ly/3u2qcob. Соцомво, Juan (1991). La jurisdicción en el derecho chileno. Santiago: Jurídica de Chile. De Gregorio, José, Annie Dufey, Óscar Figueroa, Mariana Fulgueiras, Clemente Pérez, Iván Poduje, y Violeta Rabi (2017). Transantiago, una licitación que abre oportunidades. Informe de Politicas Públicas 11. Espacio Público. Disponible en https://bit. ly/3ExQprp

Evans EspiñeIra, Eugenio y Eduardo Yáñez Rebolledo (2017). Derecho y regulación económica de la energía eléctrica. Tomo I. Santiago: Thomson Reuters.

FERradA, Juan Carlos (2014). «El panel de expertos como órgano resolutor de controversias en el mercado eléctrico: ¿ejercicio de funciones jurisdiccionales. Resolución de discrepancias en el sector eléctrico chileno: 31-50. Disponible en https://bit. ly/33NgXso.

FIORINA, Morris (1982). «Legislative choice of regulatory forms: Legal process or administrative process? «. Public Choice, 39 (1): 33-66. Disponible en https://bit. ly/32ywXxF.

García, José Francisco y Sergio Verdugo (2010). «De las Superintendencias a las Agencias Regulatorias Independientes en Chile: Aspectos constitucionales y de diseño regulatorio». Actualidad Jurídica - Universidad del Desarrollo, 11 (22): 263-305. Disponible en https://bit.ly/2KPZzK2.

Gilardi, Fabrizio (2002). «Policy credibility and delegation to independent regulatory agencies: a comparative empirical analysis». Journal of European Public Policy, 9 (6): 873-893. Disponible en https://bit.ly/3dhDZdt.

-. (2005) «THE FORMAL INDEPENDENCE OF REGULATORS: A COMPARISON OF 17 COUNtries ANd 7 SEctors». Swiss Political SCIEnce Review, 11 (4): 139-167. Disponible en https://bit.ly/37iRZje.

Gómez-Loвo, Andrés (2012). «The ups and downs of a public transport reform: The case of Transantiago». Serie Documentos de Trabajo-Departamento de Economía Facultad de Economía y Negocios Universidad de Chile, 354. Disponible en https://bit. ly/2M5QCwM. 
MaGgetti, Martino (2007). «Defacto independence after delegation: A fuzzy-set analysis». Regulation \& Governance, 1 (4): 271-294. Disponible en https://bit.ly/3pszYVM. Mardones, Rodrigo (2008). «Chile: Transantiago Recargado». Revista de Ciencia Política, 28 (1): 103-119. Disponible en https://bit.ly/3iR4oRl.

MuÑoz, Juan Carlos y Juan de Dios Ortúzar (2009). «Transantiago: The fall and rise of a radical public transport». En Wafaa Saaleh y Gerd Sammer (editores), Success and Failure of Travel Demand Management: Is Road User Pricing the Most Feasible Option? Farnham: Ashgate, Aldershot. Disponible en https://bit.ly/2MxMHZO.

PARDOW, Diego (2018a). «¿Control o autonomía? El debate sobre agencias reguladoras independientes». Revista de Derecho (Valdivia), 31 (2): 193-209. Disponible en https://bit.ly/3cg3ACQ.

-. (2018b). «¿Técnicos o políticos?: Radiografía del sistema de nombramiento de directivos en agencias regulatorias independientes». Revista Chilena de Derecho, 45 (3): 745-769. Disponible en https://bit.ly/2LYMMWv.

Puga, Diego (2017). Análisis de incentivos contractuales y propuestas para el rediseño del Transantiago. Documento de Referencia $N^{\circ} 35$ - Espacio Público. Disponible en https://bit.ly/3z4djFR.

Thatcher, Mark (2002). «Delegation to independent regulatory agencies: Pressures, functions and contextual mediation». West European Politics, 25 (1): 125-147. Disponible en https://bit.ly/3rWGJRt.

VALDivia, José Miguel (2018). Manual de derecho administrativo. Valencia: Tirant Lo Blanch.

Vergara Blanco, Alejandro (2005). «El contencioso administrativo en materia eléctrica: Naturaleza jurisdiccional de las funciones del "panel de expertos"». Revista de Derecho de la Universidad Finis Terrae, 9 (9): 207- 229. Disponible en https://bit. ly/2Zsww6t.

-. (2014). «Caracterización y líneas jurisprudenciales del panel de expertos del sector eléctrico». En Resolución de discrepancias en el sector eléctrico chileno. Santiago: Panel de Expertos - Ley General de Servicios Eléctricos. Disponible en https://bit. ly/3JsWiHk.

Rivas, Virginia (2018). «La reputación técnica y el emprendimiento de políticas como fuente de poderes: El caso de la Fiscalía Nacional Económica». Estudios Públicos, 152: 91-137. Disponible en https://bit.ly/3a56BDv.

ZÚÑIGA, Francisco (2005). «Panel de expertos: Naturaleza jurídica y ámbito de sus atribuciones». Revista de Derecho Administrativo Económico, 14: 53-64. Disponible en https://bit.ly/2YipQE3.

\section{Sobre los autores}

Pablo Muñoz Vicuña es abogado, licenciado en Ciencias Jurídicas y Sociales de la Universidad Diego Portales. Además, es magíster en Políticas Públicas de la Universidad de Chile y máster en Regulación de la London School of Economics. Actualmente, 
se desempeña como abogado de la División Jurídica de la Superintendencia de Casinos de Juego. Su correo electrónico es pablo.munoz.vicuna@gmail.com. (D) https://orcid. org/0000-0002-3403-8184.

Diego Muñoz Vicuña es abogado, licenciado en Ciencias Jurídicas y Sociales por la Pontificia Universidad Católica de Chile. Además, es magíster en Derecho Público de la Universidad Carlos III de Madrid. Su correo electrónico es diegomunozvicuna@ gmail.com. (D) https://orcid.org/0000-0002-0578-5527. 